\title{
Feminist Consciousness-Raising in The Girls from Ames
}

\author{
Salman M. Salama Abdul-Hamid ${ }^{1 \& 2}$ \\ ${ }^{1}$ Faculty of Education, Department of English Language, Damanhour University, Egypt \\ ${ }^{2}$ Faculty of Arts and Humanities, Department of English Language and Literature, Taibah University, KSA \\ Correspondence: Salman Mohammed Salama Abdul-Hamid, Faculty of Education, English Department, \\ Damanhour University, Egypt. E-mail: salmanmohamed949@hotmail.com
}

Received: October 10, 2017 Accepted: October 22, 2017 Online Published: November 2, 2017

doi:10.5539/ells.v7n4p33 URL: http://doi.org/10.5539/ells.v7n4p33

\begin{abstract}
This paper constructs the mechanisms of feminist consciousness-raising and face to face feminism as a teaching and nurturing style of life in Jeffrey Zaslow's The Girls from Ames (2009). The paper also constructs an argument that the Ames girls' less-political circle of consciousness-raising works as a social process that helps them learn from each other how to comprehend and name their experiences, and how to identify and assess their commonalities and differences. As findings, this study supports with evidence from text the powers of feminist consciousness-raising, which has been an important feminist practice since the beginning of the second feminist wave, not only in maintaining the mental and physical health of the ten women, but in helping the girls survive the challenges of their ever-changing society, build new identities and overcome their misfortunes as well.
\end{abstract}

Keywords: consciousness-raising, feminism, Jeffrey Zaslow, The Girls from Ames

\section{Introduction}

The Girls from Ames: A Story of Women and a Forty-Year Friendship is a creative non-fiction book about a group of ten women from Ames, Iowa. These women were the subject of Jeffrey Zaslow's (Note 1) 2009 nonfiction bestseller about female friendship and solidarity. In The Girls from Ames, Zaslow projects a dramatic framework upon the actual world of the Ames girls and he communicates their biographies in a way that reads like fiction. It is noteworthy that Jeffrey Zaslow was a graduate of Carnegie Mellon (Note 2), where he majored in creative writing. In this creative nonfiction, Zaslow captured the unity, mutual support and female sisterhood of the girls who formed a special circle since the age of eleven. When Zaslow started writing this nonfiction, the women were in their mid-forties. Jenny Litchman was assistant dean at the School of Medicine, University of Maryland. Jane Nash was a professor of psychology in Massachusetts. Sally Hamilton and Kelly Zwagerman were teachers in Iowa and Minnesota. Cathy Highland was a makeup artist in Los Angeles. Diana Sarussi was a Starbucks clerk in Arizona. Angela Jamison ran her own public-relations firm in North Carolina. Karla Blackwood, Karen Leininger and Marilyn Johnson were housewives in Montana, Pennsylvania and Minnesota.

In the light of the feminist practice of consciousness-raising, this study explores the world of the Ames girls in order to clarify how they skillfully apply the functions and styles of second wave and third wave feminist consciousness-raising such as forming a small group and face-to-face mutual support. In feminist doctrine, ever-changing consciousness is a basic component of social change. The researcher will prove with textual evidence how the girls developed their techniques of consciousness-raising exactly such as the concept itself evolved in feminist theory. In third wave feminism, consciousness-raising practices evolved in response to ever-changing cultural conditions. After graduation, the girls moved to eight different states and their different social contexts generated different feminist problems. This paper shows how second and third wave feminist consciousness-raising practices help the Ames girls develop a shared awareness in their public spheres, collect and analyze data and take action regarding women's experiences and understand the complicated relationships between their individual aspects of experience and economic, social conditions.

\section{Consciousness-Raising in Second Wave Feminism}

Feminist consciousness-raising groups, or CR groups, appeared in the 1960s in Chicago and New York and eventually extended over the United States. Gamble (2004) defined consciousness-raising in the following way:

Consciousness-raising (or CR) was a primary tactic of second wave feminism, which regarded it as a way 
of developing a shared consciousness of oppression among women. Consciousness-raising groups were founded on the credo that 'the personal is political,' encouraging participants to share their personal life experiences, such as childhood, motherhood and marriage. The belief was that, far from each story being individual, common patterns would emerge, thus demonstrating that female experience, rather than being exclusive to the individual, was in fact rooted in a wider system of sex inequality (p. 174).

It is believed that the second-wave of feminist activity and thought started in the early 1960s in the United States, and spread after that throughout Europe and parts of Asia. In the American context, the movement, which flourished until the early 1980s, focused mainly on female sexuality, family, civil rights and inequalities and shed the light on domestic issues and marriage/divorce laws. Larson (2014) also explained that the CR group appeared in the 1970s in the context of second wave feminism, and he defined it in the following way:

Its essential element was the use of group process for the transformation of individual awareness from a personal to a political frame of reference. Specifically, it aims to explore the origin of dissatisfaction and unhappiness that was previously experienced as resulting from a personal flaw to being the result of social oppression. It explicitly linked the broader understanding of societal structure to personal experience (p. 308).

Whether it began in the late 1960s or in the early 1970s, the feminist practice of consciousness-raising was purely political and its main target, as already shown, was to transform women awareness from the personal to the political. However, it is noteworthy that radical changes happened in the American scene regarding American women's conditions after the Civil Rights Movement in the 1960s: workplace inequality and denial of access to better jobs were dismantled, salaries witnessed much improvement, gender discrimination was prohibited, women's participation on public, social and political life was asserted and new notions started to control the image regarding women's liberation, their relationships, their sexuality, their clothing and body image and their roles in marriage. Consequently, feminist consciousness-raising started to concentrate less on politics and more on the individual particularly in the late 1970s and the1980s. The personal became no longer the political since the focus of attention was directed to the individual, namely women themselves and their lives in general.

Many literary historians believe that the second-wave feminism in the United States ended in the late 1980s which ushered the beginning of the third wave of feminist thought in the early 1990s. Consciousness-raising was celebrated by feminists in the 1970 s as a technique to give voice to and enhance women's experiences. According to the feminist doctrine of that time, consciousness-raising practices were vital in creating a critical awareness among women of their communities and cultures. It was reported that New York women's liberationist Kathie Sarachild was the person who first developed the term as a small group practice in the early 1970s (Farber, 2012). It was believed that while talking about and discussing their personal problems, women would come to understand that their personal problems were actually "social problems that must become social issues and fought together rather than with personal solutions" (Farber, 2012, p. 165). Yet, it cannot be denied that the feminist practice of consciousness-raising was known among feminists during the Civil Rights Movement in the early 1960's. They had considered the sharing of personal problems and aspirations or "telling it like it is"-could be seen as a radicalizing experience (Farber, 2012, p. 166). They also believed that by going to women themselves instead of feminists or women liberationists, women would be able to formulate new strategies and find commonalities when sharing their experiences. It was notable that affirmations of female connectedness marked the early years of the second-wave feminist movement which first began in the early 1960s in the United States and lasted through the early 1980s. This was the same span in which the Ames girls' female friendship started and flourished. Activists of second-wave feminist movement stressed the vital role of consciousness-raising, connectedness and solidarity since they were confident that these affirmations would eliminate the negative impacts of the differences that had long separated women from each other. Among the most famous slogans in Women's Movement: "sisterhood is powerful" and "none of us has made it until all of us have made it" (Code, 2006, p. 342).

Women, in the 1960s up to the 1980s, tended to share their personal experiences regarding all aspects of life. The broad topics they discussed through personal testimony in their consciousness-raising circles included discrimination; sexual life; social challenges and future aspirations. The discussions' target was to generalize experiences, abolish self-blame, unite women and let them feel that their personal experiences were not separated ones. Kamen (1991) depicts consciousness-raising in second wave feminism as a process in which women "learned to ask new questions about themselves, built self-esteem and a sense of entitlement to opportunity, gave names to their common experiences and discovered that they were not alone" (p. 4). Thus, it can be affirmed that consciousness-raising was brought to light by second wave feminists and activists as a strategy to tackle women's negative self-concepts, to alleviate the clashes between women and their patriarchal 
societies and to advocate women's rights.

\section{Consciousness-Raising in Third Wave Feminism}

The third wave of feminist thought and activism started in the late 1980s and the early 1990s and continued up to date. It focused on broad ideas such as queer theory and eliminating gender role expectations and celebrated individual differences among women instead of having one agenda for all. The movement also witnessed a growing consciousness-raising activism which played a vital role in reconstituting the meaning of women's social experience. Heywood \& Drake (2003) clarified that third wave feminism was mainly concerned with "the development of modes of thinking" in order to help women cope with an ever-changing social and political world (p. 3) Dicker \& Piepmeier (2003) also pinpointed what third wave feminism meant to contemporary women: "the third wave consists of those of us who have developed our sense of identity in a world shaped by technology, global capitalism, multiple models of sexuality, changing national demographics, and declining economic vitality" (p. 14). Apparently, there is an obvious difference between second wave and third wave feminist consciousness-raising. While second wave consciousness-raising groups tend to reinforce women's feeling of self-esteem and give names to their common experiences in the face of their patriarchal societies, third wave consciousness-raising groups keep an eye on developing women's mentalities so as to let them keep pace with their ever-changing capitalist world. The situation in the United States, in particular, was completely different after the Civil Rights Movement of the 1960s; the American scene started to be less patriarchal, women began to enjoy more freedom and we saw many women in important governmental posts. The new challenge of feminists was not stand up to their patriarchal society in order to assert their feminist identities, but rather they aimed to create new images of women as autonomous individuals who can benefit each other via sharing their experiences regarding personal and social challenges. The conversations in third wave consciousness-raising were also in private groups, through mass media, in college classrooms, or lately, through private conversations in personal emails or social media programs. Third wave feminists currently believe that the challenges of second wave consciousness-raising can sometimes be real, but they have a different mental image of their strengths, weaknesses and status since women are now surrounded by more feminist-minded people in their communities.

Due to the political, social, cultural and technological changes that the American context greatly witnessed after the 1990s, third wave consciousness-raising groups of women were mainly concerned with the new barriers of the cultural context. For Sowards \& Renegar (2004), some of challenges that third wave feminists faced in consciousness-raising included "gender inequities, feminist backlash and negative stereotypes of feminism, and a historical understanding of feminism as an exclusive movement" (p. 539). These challenges made it necessary for feminist consciousness-raising groups to exert more efforts to prove that women can be successful in any field just as men, to provide their counter argument against contemporary feminist backlash and to try to change the prejudicial notion of feminists as radical and man-hater beings. The Girls from Ames can be considered a very good example in this respect.

\section{Consciousness-Raising in The Girls from Ames}

In this section, the researcher shows how the feminist technique of consciousness-raising and female solidarity not only helped the Ames women counteract the challenges they faced, but it also provided them with comfort, security and even healing. Zaslow stated that the feminist sense was much greater among the generation of the Ames girls than the previous generations of their mothers and grandmothers because "they reached maturity in the era when feminism was blooming. So they naturally assumed that they could build sisterly bonds with friends that would feel vital and important, mirroring or contributing to the changes in society" (p. 82). Of course their mothers and grandmothers had many confidants, but "those older women didn't have the revolution of feminism to give their connections purpose and worth" (p. 82). The researcher has selected Zaslow's 2009 nonfiction bestseller, The Girls from Ames, for study and analysis in this paper since it was found to be a genre of feminist thinking in which the girls epitomized a feminist consciousness-raising group whose members shared every possible personal experience so as to help one another generalize experiences, abolish self-blame, get united and feel that their personal experiences were not separated ones. Kelly, one of the ten girls, summarized the whole situation saying: "we have lifted each other up. In every moment of grief we've shared, our laughter is a life vest, a secure promise that we will not go under" (p. 194).

\subsection{The Girls and Second Wave Feminist Consciousness-Raising}

The researcher, here, feels that it is necessary to emphasize that the essence of feminist consciousness-raising groups in the American scene after the 1980s began to be less politics-oriented. During the late 1970s and the early 1980s, "the personal" became not just "the political" and a lot of American women no longer became 
preoccupied with politics. Moreover, other topics started to govern and direct the discussions in the American circles of feminist consciousness-raising such as bachelorhood, marriage, motherhood, social challenges, sexual life, future career, health maintenance, personal growth, future aspirations and counteracting the negative stereotypical image of women. There was a widespread feminist belief in that time that coming together in the face of social fragmentation can be considered as an act of resistance (Bey, 1994). However, it cannot be denied that the 1970s political context, in which American women in general and the Ames girls in particular lived, was a bit frustrated since traditional roles for women were still expected. Unable to articulate their frustrations regarding this traditional look for women, the Ames girls initiated their feminist consciousness-raising therapy in which their goal was to analyze their situation so as to reach experiential commonalities. Only two of the girls still believed in the political role of consciousness-raising groups: Kelly's liberal political principles were shared by only some of the girls. Kelly once said "It's therapeutic to talk politics with Cathy, Jane, Angela and Sally" (p. 188), and she was so proud of Jenny who chose worked in politics at the beginning of her career. It is important to assert here that feminist consciousness-raising may sometimes be miscomprehended if considered as only political feminist reaction against patriarchy since feminism should not be grasped as a movement for the liberation of women from patriarchy only; it is a movement for the liberation of women from social-systemic domination whether this social domination is conceived as domination by men, traditions, patriarchy, or capitalism (Firth \& Robinson, 2016). Within their consciousness-raising circle, the Ames girls shared every possible experience about their personal lives. They even "shared the not-always-appreciated joys and often-exaggerated complaints about small-town life" (p. 24).

Zaslow pictured the girls' consciousness-raising approach and depicted their fruitful discussions which played a pivotal role in giving voice to and enhance the girls' experiences and in helping them formulate new strategies and find commonalities when sharing their experiences. When Zaslow wrote the book in 2009, the women were in their mid-forties. This means that their friendship nearly started in the late 1970s; the prospering period of second wave feminist consciousness-raising groups. However, most of the girls' consciousness-raising activity fell in the domain of third wave feminism which started from the early 1990s. Commenting on the 1970s which witnessed a growing feminist consciousness-raising awareness in America, Zaslow wrote:

Women were involved in a change in the culture. In talking about their own issues as mothers, wives and members of the community, they were tiptoeing into the still-being-defined women's consciousness movement. They could see that their concerns were similar to the concerns discussed by women elsewhere. Women in Ames (and beyond) were all connected to the same fabric (p. 95).

During their first phase of consciousness-raising, which was in the late 1970s and in which they exemplified the techniques of second wave consciousness-raising, the Ames girls' female connectedness played a vital role in transforming the depersonalized world of each of them into a less alienating one. In terms of the nature of consciousness-raising groups in that period of time, Baker \& Snodgrass (1979) highlighted some fundamental rules that most consciousness-raising groups had to follow:

(1) Everyone is as open and honest as possible.

(2) Confidentiality is strictly observed.

(3) No one is permitted to challenge the validity of another's experience.

(4) Equality of members is a basic precept-there is no hierarchy of power, prestige, expertise, or intelligence.

(5) Each person has an equal opportunity and amount of time to speak (p. 260).

The Ames girls' unique feminist circle began since their childhood when "the girls got to know and understand each other in part through their quirkiness" (p. 9). They were honest and open with each other, and it became clear since their first years of female sisterhood in grade school that "the way to keep female friendships alive was to listen and talk" (p. 91). In their early teens, the girls' spontaneous decision to unite and start their consciousness-raising activity was seen as a radicalizing experience. The boys at school called them "Shit Sisters" and many girls were envious on watching them together. Cathy said when she was with the other girls, "there's an understanding you don't have to explain" (p. 88). The Ames girls always felt self-assured during their meetings, and from the time they were in their early teens, they always tried to get jobs together and "each job carried its own secrets or naughty moments or lessons learned" (p. 57). By high school, the girls trusted each other deeply, and everything they carried out or revealed was expected to be kept private: "What happened in the group almost always stayed in the group" (p. 32). They trusted each other and never spilled the details of their meetings to their families or acquaintances. They were actually laying the foundation for their consciousness-raising activity that would serve them until their forties. 
Moreover, there was no hierarchy of power, status or intelligence among the Ames girls within their consciousness-raising group, and each girl had the same opportunity and amount of time to express her inner self during their gatherings. They tended to preserve a strong sense of connectedness and help each other foster personal development. They were intelligent enough to stand up to the challenges that faced consciousness-raising groups during the late 1970s and the 1980s such as women's different classes, races, religions. They cleverly put into practice Audre Lorde's maxim: "unity does not require that we be identical to each other" (Lorde, 2016, p. 320) The Ames girls were cautious enough to avoid anything that may corrupt their consciousness-raising activity. All of the girls were middle class and "there was actually an urge to downplay what they had" (p. 29). When they were young, they did not talk much about their parents' jobs, and in their forties, they did not also "brag about their husbands' jobs or incomes" (p. 211). Furthermore, the girls were also were absolute confidants to each other and no girl was allowed to question the validity of another's experience. In order to show how the Ames girls were very close and connected to each other, Zaslow wrote their names in chapter one in the following way: "KarlaSallyKarenDianaJennySheilaJaneAngelaMarilynCathyKelly, as if they were one living, breathing organism with eleven separate smiles" (p. 22).

From the very beginning of their consciousness-raising activity, the Ames girls realized the importance of socializing and sharing their personal problems and aspirations in order to formulate new strategies when sharing their experiences. They aimed "to "fix" problems by validating each other's feelings, by encouraging" (p. 92). Their teenage discussions' target was to abolish self-blame and let them feel that their personal experiences were not separated ones: "They were constantly wondering, speculating, judging, measuring. They wanted to know everything about hygiene, acne, puberty, sex, and they learned by monitoring each other" (p. 28). In high school, the eleven girls were "a closed society" or clique (p. 17), and thanks to their consciousness-raising activity and "despite a growing drug and drinking culture, Ames mostly remained unchanged" (p. 20).

During their meetings, there was much talk about gender roles and the image of true womanhood. Kelly, in particular, was "a thoughtful feminist. She'll speak without a filter and ask any question that she thinks deserves an answer" (p. 70). Kelly also kept telling the other girls "how important she felt it was to find and celebrate feminist heroes" (p. 80). In addition and for the sake of sharing experiences regarding sexual life and adulthood, she even told them that she had an abortion when she was twenty years old. She had her abortion when she was a student in the University of Iowa after sexual intercourse with her boyfriend. Kelly was not ashamed to talk about such an experience and she dreamt of the day when women would have access to legal abortions. Kelly said "I vote for candidates who defend a woman's right to have that access" (p. 80). In Kelly's viewpoint, women should have acquired a better status in society rather than the stereotypical image of them as merely mothers and housewives. She "saw no clear heroines on TV, either" (p. 79). While discussing and sharing experiences concerning the image of women in 1970s in the American context, the Ames girls speculated about "who they'd be on Gilligan's Island (Note 3), Ginger or Mary Ann - very sexy or very cute" (p. 79). Kelly decided "I guess we're all Mary Anns" (p. 79). That was the sort of women the girls were seeing on TV in the early 1970s. No program suggested that a woman could play the role of Professor on Gilligan's Island and this was the reason why Kelly told the other girls she longed for more heroines. Kelly "wondered why there weren't more female authors or African-American scientists to learn about" (p. 79). Her teacher did not comprehend her complaints and gave her just a passing grade on her essay. Undeniably, the situation changed a lot in the Ames girls' generation, and the achievements of contemporary female heroines were taught in every school, but in the 1970s, "the choices were often very male and very white. Kelly was the first of the girls to rail against that" (p. 80). When high school ended, most of the girls decided to travel to other states to join university, but "they maintained their bravado about remaining close" (p. 36). Apparently, since they started to share their experiences in their teenage years, the Ames girls learnt from one other how to comprehend and name their experiences. They discovered that they were not alone-each one of them had experiences and feelings similar to the other - and they found out that the challenges they might have faced were not the result of their inadequacies but rather of the practices of the traditional male supremacist society they lived in.

\subsection{The Girls and Third Wave Feminist Consciousness-Raising}

During the late 1980s and the early 1990s in which third wave feminist consciousness-raising started in the American context, the Ames girls were adult and mature enough to develop their modes of thinking and mentalities as a means of coping with their ever-changing capitalist society. From a women's liberation perspective, the Ames girls were a perfect example to prove that women would no longer be glued to men and alienated from each other, and they could easily form their consciousness-raising group without any mediation of men. In this phase of their consciousness-raising activity, the girls were preoccupied with two important targets: First, they strived to change the negative stereotypical image of women and to assert that they can excel in any 
field of work as men can do. Second, they insisted on maintaining a permanent and unchanging consciousness-raising activity in which they shared life's delights and sorrows regarding college, careers, marriage, motherhood, divorce and illness.

In terms of their first target that was to change the negative stereotypical image of women, it was noticed that most of the Ames girls fulfilled that goal with excellence. Jenny Litchman was a high-powered assistant dean at the School of Medicine, University of Maryland. Jane Nash got her PhD in Cognitive Psychology and became a distinguished professor of psychology in Massachusetts. Her students praised her saying: "Professor Nash is a very clear teacher... Best professor ever!” (p. 164). Kelly Zwagerman became a teacher of high-school journalism and written expression in the small town of Faribault, Minnesota. Her students considered her as "the most refreshing and inspirational teacher they've ever had" (p. 71). Sally Hamilton became a popular fifth-grade teacher in Spencer, Iowa. Cathy Highland became a popular makeup artist in Los Angeles; she toured the world with the American singer Janet Jackson and worked with the casts of many popular American sitcoms. Diana Sarussi was a well-loved Starbucks clerk in Arizona. She was such an illustrious clerk that she devised a plan for a successful recycling program at Starbucks. Angela Jamison ran her own profitable public relations business in North Carolina, and she made up her mind to create a second business. Even Karla Blackwood, Karen Leininger and Marilyn Johnson, who were housewives in Montana, Pennsylvania and Minnesota, remained a great source of motivation and encouragement for the rest of the girls to outdo in their fields of work.

Apropos their second target which was to maintain a permanent consciousness-raising activity in which they could share their personal experiences about college, careers, marriage, motherhood, divorce and illness, the Ames girls succeeded in moving from the world of personal experiences to the broader world of collective awareness and they adopted an effective consciousness-raising strategy which was: "Love. Support. Advice. Action. What's the problem? What's the solution?" (p. 218). Although the girls moved to eight different states in order to complete their university studies and work, they were always keen on keeping in touch. Just before Zaslow wrote the book, they reunited for a four-day weekend at Angela's just to "to share tentative predictions and yearnings about what's ahead in each of their lives" (p. 24). They used to gather like this during all their adult lives, and when they were in each other's company, they saw "themselves through thousands of shared memories" (p. 24). Their gathering was a process of feminist pedagogy in which the Ames girls talked and exchanged pieces of advice about everything that may concern a girl or a woman. They frequently discussed the topic of marriage and how it was difficult to find suitable men with the character traits and merits they were looking for. In other times, they tackled several other topics related to health; "the conversation morphs into a discussion about body image, dieting and the new horizons of healthful eating" (p. 127). They even shared their own personal experiences regarding pop-culture, and they were each other's pop-culture monitor. This was so clear when they "spent their lives trading stories of fads worth emulating, singers worth appreciating and their own celebrity sightings" (p. 127).

The girls also stood by one another's side and spared no efforts in providing counseling and sharing personal experiences in times of emotional traumas. For instance, when Kelly got divorced, she found comfort in her presence in the girls' circle of discussion. The Ames girls played an important role in helping Kelly overcome her emotional trauma as they "resisted being judgmental, and occasionally shared a helpful story of divorce that their siblings or other relatives went through" (p. 183). Karla and Angela also got divorced and remarried, and they stood by Kelly's side and "were able to offer Kelly their perspective that light comes after darkness" (p. 184). When they spoke to her, Kelly reflected on: "It's comforting to have people who can give you stories that make a difference when it's so bleak" (p. 184). Kelly sometimes felt hopeless and confused, but owing to her supportive circle of consciousness-raising, she felt "embraced and loved. And that sustained her" (p. 184).

In addition, the girls were keen on widening the process of knowledge-creation via sharing personal experiences while discussing other feminist topics such as motherhood and parenting. As mothers, the girls were a great source of help for each other when directly disclosing the effective methods that assisted them in bringing up their children. They shared their experiences and pieces of advice, even through emails when they could not meet in person. Kelly's emails to everyone else often "became impassioned essays about the uncertainties of womanhood and motherhood" (p. 73). When the other girls read her emails in their homes across the United States, they "couldn't help but think about their own children and the safety lessons ahead" (p. 74). As a teacher, Sally also shared with the girls lessons about the stresses of motherhood. Jane once said that the distance between all of the Ames girls did them a great favor as it made them closer in certain ways. They became very attentive listeners to each other and they had a heap of opinions and pieces of advice that could benefit them a lot as mothers. Simply, it was the fruitage of "nine other women weighing in about adult issues, with more than twenty kids' worth of experience when it comes to children's issues" (p. 90). Kelly, who had no actual sisters and 
preferred not to remarry, said that it was her friends from Ames who exposed her "to every facet of womanhood" (p. 90).

The girls' shared experience of motherhood was also greatly influenced by Karla's devotion to her family, especially when Christie, Karla's first daughter, was diagnosed with leukemia. This situation greatly highlighted the girls' weaving together of experiences and breaking down of emotional alienation. They realized that a true consciousness-raising activity meant "a willingness to share both joy and complete despair" (p. 149). For example, Karla felt so much relieved on sharing every simple detail with the girls. Sally did change a lot "into a better, more patient, more loving mother" and "a better, more patient teacher, too" (p. 144).

Concerning parenting, the Ames girls often gave each other pieces of advice on how to bring up their children. Jane said "Cooperation and appreciation... That's my mantra" (p. 159). Jane advised the other girls that she kept repeating the same words to her children. "I tell them all the time: I want them to cooperate and I want them to appreciate" (p. 159). From the moment Karla delivered Christie in 1990, "the girls have been trading an unending procession of motherhood tales" (p. 161). As soon as they got email accounts, the Ames girls started asking each other for instant advice regarding their kids. One of girls once had questions about attention deficit disorder and teens. Immediately, "Sally and Kelly weighed in as teachers. Cathy offered nutritional advice. Everyone had thoughts" (p. 162). The sibling rivalry between Kelly's two sons led to a lot of arguing and physical fights and was discussed as a topic among the girls. The girls reacted quickly and tried to share their ideas regarding the matter. After joining a parenting group which recommended a certain book on sibling rivalry, Diana sent Kelly the book as a present and it saved her. Apparently, in the company of each other, the Ames girls learned practical lessons and formed collective awareness on issues related to motherhood.

The Ames girls realized that through their consciousness-raising activity, through listening and talking to each other, they could even maintain their physical health. Several feminist theorists wrote about the unbelievable powers of female connectedness and solidarity in feminist consciousness-raising groups. Feminist therapy was a term which highlighted the therapeutic impacts of consciousness-raising and female connectedness on the lives of women. Code (2006) drew the attention to the fact that "a lifetime of job interruptions and of stress from juggling family duties with paid employment often impairs women's mental and physical health" (p. 408). As a result, "In the 1980s, with the rise of cultural feminism, prominent feminist therapies focused on fostering women's "relationality" and "connectedness"” (p. 389) as an effective way through which women mutually take care of one another's mental and physical health. Undoubtedly, the empathetic role of feminist circles of consciousness-raising during tough times of ailments was considered an extremely powerful feminist act. Code (2006) also affirmed that "Women have always been involved in health and healing, particularly in providing assistance to each other" (p. 205). The mutual counseling and support that the girls found in consciousness-raising and arguing with each other were useful and effective ways to preserve their sanity and physical health. They felt the necessity to stay connected particularly in their twenties and thirties because these were the years in which they stared their careers, got married and had babies.

The Ames girls' wise decision to break the silence about their health problems had a very positive impact on their lives. Marilyn once said, "It's good for my mental health to know there's a group of people I can turn to at any moment in my life, and they'll be my safety net" (p. 89). When Jenny had two miscarriages, Karen helped her by talking about her own experience of losing a child and this comforted Jenny greatly. In addition, the Ames girls often exchanged personal experiences in times of illness or health problems. When Kelly sent an email to all the other girls telling them that she has breast cancer, the girls began immediately to share their experiences to help her stand up to this challenge. For example, "Karla offered to share all the medical knowledge she'd gathered during Christie's illness, and reminded Kelly to get a flu shot and to have her kids do the same" (p. 218). Thanks to her job at the medical school, Jenny also had much counseling to offer Kelly concerning the best medical center to go. When Angela, too, had breast cancer, all the girls responded quickly sharing very useful pieces of advice which formed a collective awareness that helped Angela greatly and was beneficial to her health. Thus, reading The Girls from Ames from a third wave feminist perspective highlighted the vital role played by consciousness-raising in the development of the girls' modes of thinking and in reinterpreting their personal experiences from a female perspective. Through their constructive feminist consciousness-raising practices, the Ames girls could recount and interpret their experiences and reflections around a specific topic, and then they drew out commonalities and succeeded in combining their personal experiences into a structural picture. Zaslow brilliantly chronicled how the Ames girls' numerous personal experiences intermingled and processed in their consciousness-raising group setting, and how this saved them from isolation, enabled them to feel less alienated from one another and fostered their sense of connectedness and trust. 


\section{Conclusion}

To sum up, The Girls from Ames exemplified an effective feminist consciousness-raising group in which the Ames girls shared their personal experiences regarding the personal and social challenges they faced. During their second wave feminist consciousness-raising phase in the 1970s and the 1980s, the girls learned to ask questions about their lives, to build self-esteem, to give names to their experiences and to realize that they were not alone. While in their third wave feminist consciousness-raising phase after the 1990s, the girls could formulate new strategies and find commonalities when sharing their personal experiences so as to develop their modes of thinking as a means of coping with their ever-changing capitalist society. They succeeded in proving that the personal experience of any individual woman could be instructive for other women. In the course of their consciousness-raising activity, the Ames girls usually started by selecting a topic related to women's experience, such as marriage, dating, motherhood, children, abortion, or a variety of other issues, and then each of them began to speak about the chosen topic and no one dominated the discussion. The technique was very successful in the girls' lives since it saved them from the dangerous feelings of alienation and isolation from which many contemporary women suffer and it also worked as a psychological therapy during hard times of social and personal challenges. Moreover, the girls' consciousness-raising practices created among them a sense of sisterhood which helped them verbalize their feelings and overcome their own inadequacies. This, of course, was accompanied by a high level of commitment on the part of the Ames girls to speak and act honestly and nonjudgmentally.

\section{References}

Baker, D., \& Snodgrass, J. (1979). Team Teaching a Sociology of Sex Roles Seminar: Using Consciousness-Raising Methods. Teaching Sociology, 6(3), 259. https://doi.org/10.2307/1317306

Bey, H., \& Baer, F. (1994). Immediatism: essays by Hakim Bey. Edinburgh, Scotland: AK Press.

Code, L. (2006). Encyclopedia of feminist theories. London: Routledge.

Farber, D. R. (2012). The Sixties: from memory to history. Chapel Hill: University of North Carolina Press.

Firth, R., \& Robinson, A. (2016). For a revival of feminist consciousness-raising: horizontal transformation of epistemologies and transgression of neoliberal TimeSpace. Gender and Education, 28(3), 343-358. http://dx.doi.org/10.1080/09540253.2016.1166182

Gamble, S. (2004). The Routledge companion to feminism and postfeminism. London: Routledge.

Henry, A. (2003). Feminism's family problem: Feminist generations and the mother-daughter trope. In R. Dicker \& A. Piepmeier (Eds.), Catching a wave: Reclaiming feminism for the 21st century (pp. 209-231). Boston: Northeastern University Press.

Heywood, L., \& Drake, J. (2003). Third wave agenda: being feminist, doing feminism. Minneapolis: University of Minnesota Press.

Kamen, P. (1991). Feminist fatale: voices from the "twentysomething" generation explore the future of the “women's movement". New York, NY: Donald I. Fine.

Larson, P. (2014). Consciousness-Raising Groups. Encyclopedia of Critical Psychology, 308-311. https://doi.org/10.1007/978-1-4614-5583-7_603

Lorde, A. (2016). I Am Your. Sister: Black Women. Organizing Across. Sexualities. In C. McCann \& S. Kim, Feminist Theory Reader: Local and Global Perspectives (4th ed., pp. 320-325). New York: Routledge.

Sowards, S. K., \& Renegar, V. R. (2004). The rhetorical functions of consciousness - raising in third wave feminism. Communication Studies, 55(4), 535-552. https://doi.org/10.1080/10510970409388637

Zaslow, J. (2010). The girls from Ames: a story of women and a forty-year friendship. New York, NY: Gotham Books.

\section{Notes}

Note 1. Jeffrey Lloyd Zaslow (October 6, 1958- February 10, 2012) was an American author, journalist and columnist. He used to write for The Wall Street Journal. Zaslow individually authored some books, such as Tell Me All About It (1990), The Girls from Ames (2009), and The Magic Room (2012). He coauthored some bestsellers including: The Last Lecture (2008), Highest Duty: My Search for What Really Matters (2009), and Gabby: A Story of Courage and Hope (2011). 
Note 2. Carnegie Mellon University is a worldwide university in Pittsburgh, Pennsylvania. It was founded in 1900 by Andrew Carnegie, and it became known as Carnegie Mellon University in 1967. CMU usually ranks in the top 25 in the national U.S. News \& World Report rankings and it is famous for its interdisciplinary programs: humanities, arts, business, engineering, policy and science.

Note 3. Gilligan's Island is an American situation comedy created by Sherwood Schwartz. It was broadcasted for three seasons from September 26, 1964, to April 17, 1967. The show was about the comic adventures of seven castaways trying to survive on an island after they had been shipwrecked.

\section{Copyrights}

Copyright for this article is retained by the author, with first publication rights granted to the journal.

This is an open-access article distributed under the terms and conditions of the Creative Commons Attribution license (http://creativecommons.org/licenses/by/4.0/). 